\title{
Erhöhtes Risiko für Typ-1-Diabetes bei Babys dicker Mütter
}

Fragestellung: Ist das Risiko für einen Typ-1-Diabetes bei Nachkommen von Müttern mit Übergewicht/Adipositas - mit und ohne Diabetes - und bei verschiedenen Ethnizitäten erhöht?

Hintergrund: Die Inzidenz des Typ-1-Diabetes bei Kindern in Schweden steigt, genauso wie die Prävalenz von Übergewicht und Adipositas bei Schwangeren.

Patienten und Methoden: Diese Studienkohorte umfasste 1263358 Kinder, die in Schweden zwischen 1992 und 2004 geboren wurden. Die Kinder wurden beobachtet von der Geburt hin bis zur Diagnose Typ-1-Diabetes, bis zur Emigration, oder Tod oder dem Beobachtungsende 2009, was auch immer zuerst eintrat. Der mütterliche Body-Mass-Index $\left(\mathrm{kg} / \mathrm{m}^{2}\right)$ im ersten Trimester und die Inzidenzratios (IRRs) mit 95\%-KI für Typ-1-Diabetes der Nachkommen (Poisson-Regression) wurden berechnet.

Ergebnisse: Das Risiko für Typ-1-Diabetes war unabhängig von der Ethnizität erhöht, wenn die

Hussen HI, Persson M, Moradi T. Maternal overweight and obesity are associated with increased risk of type 1 diabetes in offspring of parents without diabetes regardless of ethnicity. Diabetologia 2015;58:1464-73.
Eltern irgendeine Form von Diabetes mellitus hatten. Ein hoher BMI im ersten Trimester war mit einem erhöhten $\mathrm{Ri}$ siko für Typ-1-Diabetes assoziiert, aber nur dann, wenn die Eltern keinen Diabetes hatten (IRR 1,33 [95\%-KI 1,20-1,48]).

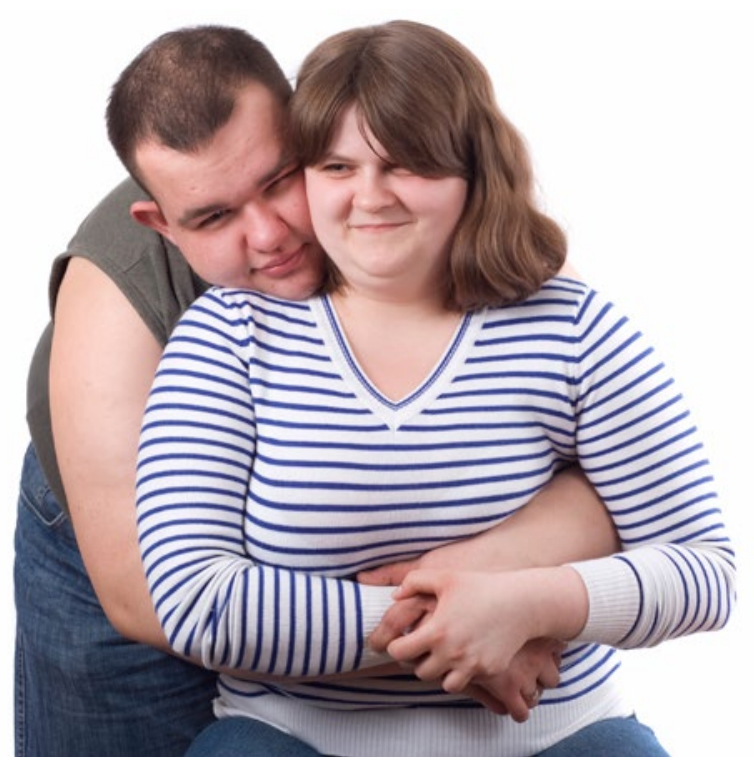

Übergewichtig und guter Hoffnung? Möglicherweise wird dem Kind nicht nur ein erhöhtes Typ-2- sondern auch ein erhöhtes Typ-1-Diabetesrisiko in die Wiege gelegt.

Schlussfolgerung: Die steigende Inzidenz an Typ-1-Diabetesmellitus bei Kindern nicht diabetischer Eltern könnte teilweise dadurch erklärt werden, dass die Prävalenz von Übergewicht und Adipositas bei den Müttern zunimmt.

\section{- Kommentar Prof. Dr. med. Nanette C. Schloot}

\section{Eventuell ist die Epigenetik entscheidend}

Bisher ist nicht geklärt, warum die Inzidenz des Typ-1-Diabetes jährlich um ca. 4\% zunimmt. Genetische Faktoren können dies nicht erklären, sodass nach Faktoren aus der Umwelt gesucht wird. Die hier vorgelegte Studie bestätigt, dass ein Typ1-Diabetes der Eltern das höchste Risiko mit sich bringt, dass auch die Kinder einen Typ-1-Diabetes entwickeln, was gut durch die genetisch bedingte Prädisposition erklärt ist.

Interessant ist aber die Beobachtung, dass Übergewicht/Adipositas bei den nicht diabetischen Eltern auch zu vermehrtem Typ-1-Diabetes bei den Nachkommen führen. Eventuell spielt hier die Epigenetik eine Rolle, die die intrauterine Umgebung von adipösen Müttern beeinflussen könnte und Betazellstress, metabolische Dysregulation und frühere Manifestation eines Typ-1-Diabetes bei suszeptiblen Kindern bewirken könnte. Studien bei älteren Patienten mit Typ-1-Diabetes bestätigen ebenfalls eine große Bedeutung des BMI beim Betazellverlust, z.B. [1]. Für Kinder adipöser Mütter ist zudem beschrieben, dass es bereits früh zu einer Insulinresistenz kommt.

\section{Literatur}

1. Lauria A, Barker A, Schloot N et al. BMI is an important driver of $\beta$-cell loss in type 1 diabetes upon diagnosis in 10 to 18-year-old children. Eur J Endocrinol. 2015 Feb;172(2):107-13.

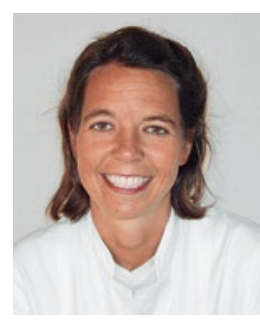

Prof. Dr. med. Nanette C. Schloot

\section{Deutsches Diabetes-Zentrum}

Institut für Klinische Diabetologie an der Heinrich-Heine Universität Düsseldorf Nanette.Schloot@DDZ.uni-duesseldorf.de 